\title{
Traditional Chinese Medicine Daitai for Use in the Prevention of Porcine Reproductive and Respiratory Syndrome
}

\author{
Chuantian $\mathrm{Xu}^{1}$, Mei Lu ${ }^{2}$, Beixia $\mathrm{Hu}^{1}$, Qinggui Lu ${ }^{3}$, Xiumei Zhang ${ }^{{ }^{*}}$ \\ ${ }^{1}$ Institute of Animal Science and Veterinary Medicine, Shandong Academy of Agricultural Sciences, Jinan, China \\ ${ }^{2}$ Weifang College of Education, Qingzhou, China \\ ${ }^{3}$ Weifang Noted Pharmaceutical Co., LTD, Qingzhou, China \\ E-mail: ${ }^{*} x c t t a i a n 2002 @ 163 . c o m$
}

Received May 24, 2011; revised August 10, 2011; accepted August 24, 2011

\begin{abstract}
To find an effective prevention method for porcine reproductive and respiratory syndrome (PRRS), three indices from experimental and control group pigs, namely, routine blood index, serum biochemical indicators, and conventional cell factor contents of serum, are inspected. The prevention and treatment of PRRS effect are evaluated, feeding pigs with Daitai. Results show that traditional Chinese medicine (TCM) Daitai can significantly improve the nonspecific immunity of pigs.
\end{abstract}

Keywords: PRRS, Traditional Chinese Medicine, Nonspecific Immunity, Viral Disease

\section{Introduction}

For nearly 30 years, the breeding industry in China has developed rapidly at an unceasingly expanding scale and with constantly updated equipment. China has therefore become a breeding superpower, but its breeding quality requires further enhancement. At present, an uneven management level exists in domestic cultivation, and new diseases emerge while old illnesses are still rampant. Biological safety measures are currently non-existent. Therefore, the domestic breeding environment has become very poor. For example, in 2006, a porcine reproductive and respiratory syndrome (PRRS) disease outbreak occurred in China and has since been continuing to devastate the porcine industry, resulting in substantial economic losses [1-3]. However, no special vaccines have been developed yet, and pig diseases treated using traditional antibiotics have yielded poor outcomes. As a result, a large number of pigs died rapidly after being given traditional antibiotics. Confronted with PRRS, farmers burned pig carcasses, and veterinary experts, scientific research personnel, and vaccine and veterinary medicine manufacturers were placed in a very embarrassing situation because of their apparent inability to mitigate the situation. Facing this reality, a number of options were considered, including providing pigs with a relatively comfortable environment or leaving them to fend on their own. Although advanced equipment paved the way for the modernization of breeding, these devices merely affected the external environment. However, the primary concern of many breeders was the inability to raise pigs well because of the large number of porcine diseases. Based on blood routine indices, biochemical indicators, and cell factor content testing used in the analysis of the experimental and the control groups of pigs, the prevention and the treatment of PRRS were evaluated. The current study discusses the systemic principles of traditional Chinese medicines (TCMs) that can be applied for the enhancement of the animal husbandry industry.

\section{Materials and Methods}

Experimental groups I, II, and III and the control group contain three-month-old piglets, with 30 heads in each group. Tested pigs were fed with Daitai, with $1 \mathrm{~kg}$ of Daitai added to each ton of feed. On the other hand, control group pigs were given feed without Daitai. Daitai was provided by Weifang-Noted Pharmaceuticals Co., LTD and was composed of the following primary ingredients: astragalus, radix scutellariae, barrenwort, licorice, and so on.

Experiment I. Routine blood test: one month after acquisition, each pig undergoes a routine blood test for anticoagulation. 
Experiment II. Serum biochemical index test: one month after acquisition, serum is extracted from each pig to determine biochemical index.

Experiment III. Cytokine detection: one month after acquisition, serum is extracted from each pig to detect cytokine content. An ELISA kit from an American R \& D company was used for the detection of IL-2 and TNF alpha. A detection method was employed based on the kit. Selected equipment and anticoagulants were provided by the People's Hospital of Qinzhou, and the routine blood test and biochemical indices required for Experiments I and II were tested by the same hospital.

Experimentl IV. The effect of Daitai on the prevention of PRRS: pigs in the experimental and control groups all originated from Qingzhou City, Shandong Province, where PRRS was rampant in 2009. The experimental group included 46 sows, 80 piglets, and 72 breeding pigs, all of which were fed with Daitai (1 kg Daitai additives for every ton of feed). The control group included 80 sows, 150 piglets, and 93 breeding pigs.

PRRS case treatments: 1) Daitai (1 kg) + glucose (30 kg) + multivitamins, with a sufficient amount of water, produced $1000 \mathrm{~kg}$ of drinkable mixture, which was given to the pigs daily for seven days; 2) Traditional treatment, antivirus, antiphlogistic, rehydration, control of secondary infections.

\section{Results}

\subsection{Routine Blood Test Results}

In Table 1, conventional indices of the blood of the experimental pigs are within normal range. However, in the control group, leukocyte count, red blood cell count, hemoglobin, and deposited red blood cells were lower than the normal reference index. The platelet index was higher than the reference index by more than ten times. Hemoglobin was of clinical significance, indicating mild anemia or abnormal liver function. High platelet count indicated the presence of myeloid proliferative diseases, such as chronic granulocyte leukemia, and diseases indicated by an increased number of true red blood cells, such as early myelofibrosis, acute infection, and acute hemolysis, as well as certain cancers.

\subsection{Serum Biochemical Index Test}

In Table 2, sera extracted from the experimental pigs are within normal range, as seen in the conventional index. However, in the control group, aspertate aminotransferase and alkaline phosphatase were significantly higher than the normal reference index, and the total protein indicator index was lower than the normal references.
The clinical significance of high alkaline phosphatase is biliary dysfunction, and high aspertate aminotransferase indicates abnormal liver function. A low total protein level results in water natrium retention. Generally, abnormal liver function is the primary factor that results in low total protein.

\subsection{Cytokine Detection}

In Figure 1, the tumor necrosis factor (TNF) content in the experimental group is 32 times that of the control group, and interleukin 2 (IL-2) content is 1.85 times that of the control group. Therefore, after the addition of Daitai to the experimental group feed, two serum cytokine levels of this group evidently improved compared with those of the control group.

\subsection{Daitai Prevention PRRS Effect}

A large number of pig farms went bankrupt because of the PRRS outbreak in 2009. The mortality of pigs fed with Daitai was significantly lower than that of the control group. Even after ictus, the use Daitai for PRRS

Table 1. Results of routine blood tests.

\begin{tabular}{cccccc}
\hline & $\begin{array}{c}\text { Numeration } \\
\text { of } \\
\text { Leukocyte } \\
(109 / \mathrm{L})\end{array}$ & $\begin{array}{c}\text { Red Blood } \\
\text { Cell } \\
(1012 / \mathrm{L})\end{array}$ & $\begin{array}{c}\text { Hemoglobin } \\
(\mathrm{g} / \mathrm{L})\end{array}$ & $\begin{array}{c}\text { Red } \\
\text { Blood } \\
\text { Cells } \\
\text { Deposited } \\
\%\end{array}$ & $\begin{array}{c}\text { Platelet } \\
(109 / \mathrm{L})\end{array}$ \\
$\begin{array}{c}\text { Normal } \\
\text { Reference } \\
\text { Index }\end{array}$ & $\begin{array}{c}13.1- \\
14.95\end{array}$ & $5.17-5.85$ & $98.6-136$ & $35-43$ & $150-450$ \\
$\begin{array}{c}\text { Experimental } \\
\text { Group }\end{array}$ & 12.35 & 5.76 & 130 & 43 & 207 \\
Control & 11.4 & 4.87 & 78 & 30.54 & 1757 \\
Group & & & & & \\
\hline
\end{tabular}

Table 2. Results of the serum biochemical index test.

\begin{tabular}{ccccc}
\hline & $\begin{array}{c}\text { Glu- } \\
\text { tamic-Pyruvic } \\
\text { Transaminase } \\
(\mathrm{U} / \mathrm{L})\end{array}$ & $\begin{array}{c}\text { Glutamic- } \\
\text { Oxalacetic } \\
\text { Transaminease } \\
(\mathrm{U} / \mathrm{L})\end{array}$ & $\begin{array}{c}\text { Alkaline } \\
\text { Phosphatase } \\
(\mathrm{U} / \mathrm{L})\end{array}$ & $\begin{array}{c}\text { Total } \\
\text { Protein } \\
(\mathrm{g} / \mathrm{L})\end{array}$ \\
\hline $\begin{array}{c}\text { Normal } \\
\text { Reference } \\
\text { Index }\end{array}$ & $31-58$ & $30-61$ & $35-110$ & $79-89$ \\
$\begin{array}{c}\text { Experimental } \\
\text { Group }\end{array}$ & 44.1 & 57 & 74.7 & 79.3 \\
Control \\
Group
\end{tabular}

The normal reference index in Table 2 is from "Veterinary Medicine Laboratory Testing Technology" [4]. 
treatment evidently yielded better outcomes compared with the use of traditional treatments. An obviously lower attrition rate versus the control group was also observed (Figure 2).

\section{Discussions}

Routine blood and serum biochemical indicators of experimental pigs were within normal range (Tables 1 and 2). In the control group, Daitai was not used, and the routine blood and the serum biochemical indices were either higher or lower than the normal reference index, a subhealth state, indicating high susceptibility to the disease. The use of TCM products for pigs ensured recuperation through nonspecific immunity and improvement of conditions. It also ensured that visceral function and routine blood and biochemical indicators were within a normal range.

In the experimental group fed with Daitai, PRRS prevention efficiency reached 93\%, which was markedly higher than that of the control group (53\%). Moreover, the cure rate reached $75 \%$, also higher than that of the control group (43\%). An obviously lower attrition rate was also observed versus the control group (Figures 2 and 3), which is related to routine blood and biochemical indicators (Tables 1 and 2). This result can be attributable to improved health, with each organ functioning normally, as opposed to a sub-health state, wherein visceral

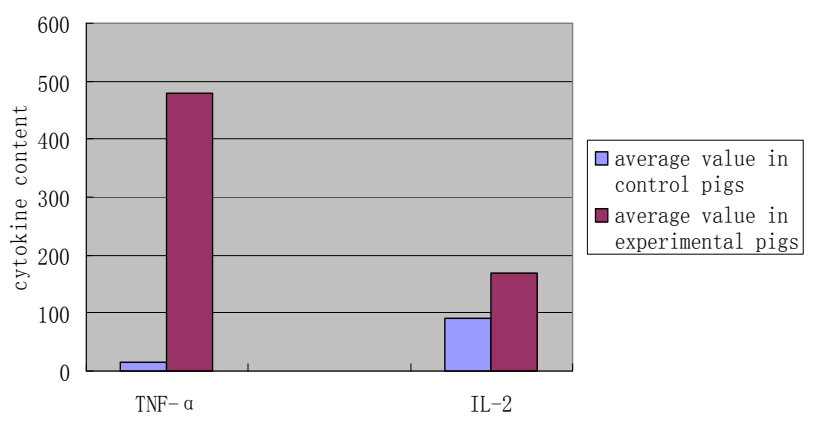

Figure 1. Cytokine detection results.

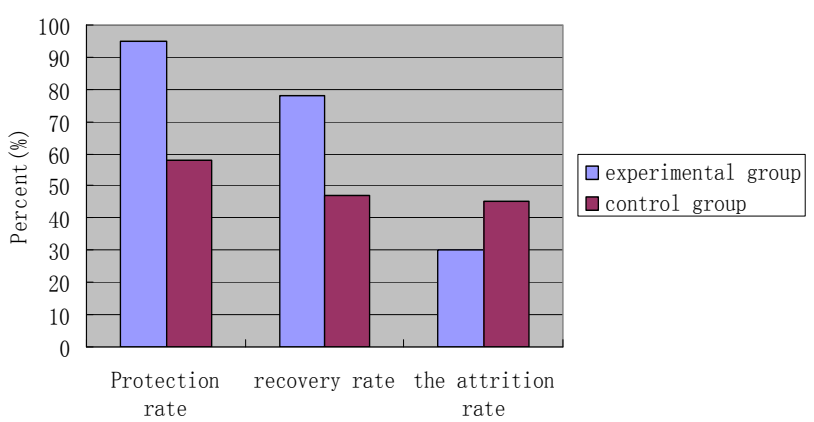

Figure 2. Protection and attrition rates for experimental and control pigs infected with PRRS. functions are not normal. Therefore, with the use of Daitai, the chances of contracting the disease are smaller.

To elaborate the effect of Daitai on PRRS prevention, two primary cell factors (IL-2 and TNF alpha) were tested in the experimental and the control swines.

IL-2 is the body's most powerful T cell growth factor, which safeguards normal immune functions, enhances $\mathrm{T}$ cell killer activity through group-cloned amplification, and improves and strengthens immune functions. Various cells are induced or activated by IL-2 (such as toxicity, CTL, LAK, NK, and TIL). LAK is lymphatic cell, which, after contact with IL-2, produces efficient killer cells with anti-tumor effects. IL-2 also affects B cell growth and differentiation, and stimulates macrophages, improving their scavenging capability. IL-2 can also induce $\mathrm{T}$ cells to secrete IFN-gamma, TNF, and CSF cell factors.

TNF alpha is a mononuclear factor, which is primarily produced by mononuclear cells and macrophages. In addition, neutrophils, LAK, satellite cells, endothelial cells, and smooth muscle cells can also produce TNF alpha $[5,6]$. TNF can kill certain tumor cells (cytolytic action) by inhibiting their proliferation action (cytostatic action) in vitro and in vivo [7,8]. TNF can directly kill cancer cells. TNF also has a similar IFN antiviral effect, preventing early protein synthesis of the virus, thus inhibiting virus replication and killing cells infected by the virus.

Figure 1 shows that the Daitai can increase IL-2 and TNF alpha content of pig sera, which cannot only enhance organism nonspecific immunity functions, but can also inhibit early protein synthesis of the virus, inhibiting duplication. Thus, the animal virus cannot survive. This finding can also explain why the experimental group pigs in Figure 2 can resist the attack of the PRRS virus effectively at the cellular and the molecular levels.

The TCM product, Daitai, has obvious clinical effects on the prevention of PRRS, and this preventive effect was tested through the continuous use of Daitai over one month. The test proved that TCM constantly adjusts the immune position of animals, improving organ functions by mobilizing the immune system against external microbial infection. On the other hand, TCM plays an important role in enhancing various physiological animal functions even in the absence of disease if used over a period of time, by acting against external biological invasion, which is really a good method for prevention in terms of modern veterinary biological safety measures. The "prevention first" concept should also be developed, not just from the external environment, but by also considering the internal functions of animals. Although considering the external environment is important, external biology only affects an animal's body slightly, but if an 
excellent living space is provided, animals enjoy a great deal of benefits, and human beings also reap bigger and longer-term breeding advantages.

In fact, studies on TCM therapy for viral diseases are popular [9-15]. For the treatment of PRRS, many reports on TCM are available, especially when its clinical effect receives recognition from veterinary experts. This experiment again proved that TCM indeed has a unique treatment effect on viral diseases and can be used as a potential drug for treatment of future viral diseases when providing a new and convenient treatment approach is difficult.

The detection of a large number of biochemical indicators and cytokines may result in the improvement of TCM products, but details on the nonspecific immunity mechanism of TCM are still unclear. The Chinese medicine theory is complex. To date, many scholars worldwide are studying Chinese medicine. Therefore, although the mechanism of the effects of Daitai in the adjustment of the immune function in animals remains unknown, perhaps the "overall, TCM theory of dialectical” mysteries may someday come to light, and the role of TCM in the enhancement of Western medicine may be explained. Science is science, despite limited evidence, and this principle also holds true for TCM.

Daitai undeniably functioned as a form of TCM with its system enhancing effect, which has yielded very good outcomes in the prevention of PRRS, which benefitted livestock producers.

\section{References}

[1] J. Wu, J. Wang, Y. Liu, W. Wang, X. Zhang and D. Yoo, "Relationship between Herd Size and the Prevalence of PRRS in Pig Herds in China," Veterinary Record, Vol. 163, No. 3, 2008, pp. 90-91. doi:10.1136/vr.163.3.90

[2] K. Tian, X. Yu, T. Zhao, Y. Feng, Z. Cao, C. Wang, et al., "Emergence of Fatal PRRSV Variants: Unparalleled Outbreaks of Atypical PRRS in China and Molecular Dissection of the Unique Hallmark," PLoS One, Vol. 2, No. 6, 2007, p. e526. doi:10.1371/journal.pone.0000526

[3] S. H. Cha, E. J. Choi, J. H. Park, S. R. Yoon, J. Y. Song, J. H. Kwon, et al., "Molecular Characterization of Recent Korean Porcine Reproductive and Respiratory Syndrome (PRRS) Viruses and Comparison to Other Asian PRRS Viruses," Veterinary Microbiology, Vol. 117, No. 2-4, 2006, pp. 248-257. doi:10.1016/j.vetmic.2006.05.007

[4] J. D. Wang, "Veterinary Medicine Laboratory Testing Technology,” Journal of Chinese Agricultural Science and Technology Press, Vol. 1, 2005, pp. 185-186.

[5] M. Buttini, K. Appel, A. Sauter, P. J. Gebicke-Haerter and H. W. Boddeke, "Expression of Tumor Necrosis
Factor Alpha after Focal Cerebral Is Chaemia in the Rat," Neuroscience, Vol. 71, No. 1, 1996, pp. 1-16. doi:10.1016/0306-4522(95)00414-9

[6] M. Pinzani, F. Marra and V. Carloni, "Signal Transduction in Hepatic Stellate Cells," Liver, Vol. 18, No. 1, 1998, pp. 2-13. doi:10.1111/j.1600-0676.1998.tb00120.x

[7] R. F. Schwabe and D. A. Brenner, "Mechanisms of Liver Injury. I. TNF-Alpha-Induced Liver Injury: Role of IKK, JNK, and ROS Pathways," American Journal of Physiology-Gastrointestinal and Liver Physiology, Vol. 290, No. 4, 2006, pp. 583-589. doi:10.1152/ajpgi.00422.2005

[8] A. L. Siren, Y. Liu, G. Feuerstein and J. M. Hallenbeck, "Increased Release of Tumor Necrosis Factor-Alpha into the Cerebrospinal Fluid and Peripheral Circulation of Aged Rats,” Stroke, Vol. 24, No. 6, 1993, pp. 880-886. doi:10.1161/01.STR.24.6.880

[9] Y. Liu, J. Liu, P. Yin, M. Gao, C. Deng and X. Y. Zhang, "High Throughput Identification of Components from Traditional Chinese Medicine Herbs by Utilizing Graphene or Graphene Oxide as MALDI-TOF-MS Matrix," Journal of Mass Spectrometry, Vol. 46, No. 8, 2011, pp. 804-815. doi:10.1002/jms.1952

[10] X. Cui, Y. Wang, N. Kokudo, D. Fang and W. Tang, "Traditional Chinese Medicine and Related Active Compounds against Hepatitis B Virus Infection,” BioScience Trends, Vol. 4, No. 2, 2010, pp. 39-47.

[11] A. Li, Y. Xie, F. Qi, J. Li, P. Wang, S. Xu, et al., "Anti-Virus Effect of Traditional Chinese Medicine YiFu-Qing Granule on Acute Respiratory Tract Infections," BioScience Trends, Vol. 3, No. 4, 2009, pp. 119-123.

[12] S. H. Huang, X. L. Feng, L. L. Zhang, S. P. Xu, C. Y. Wu and W. Wei, "Antiviral Effects of an Effective Section of a Prescription of Traditional Chinese Medicine on Influenza Virus A in vitro,” Zhong Yao Cai, Vol. 32, No. 3, 2009, pp. 391-394.

[13] Y. M. Li, H. Z. Yang, W. B. Guan, Q. S. Ke, M. Dai, H. P. Xie, et al., "Therapeutic Effect of Traditional Chinese Medicine on Coagulation Disorder and Accompanying Intractable Jaundice in Hepatitis B Virus-Related Liver Cirrhosis Patients,” World Journal of Gastroenterology, Vol. 14, No. 39, 2008, pp. 6060-6064. doi:10.3748/wjg.14.6060

[14] H. Y. Cheng, H. H. Huang, C. M. Yang, L. T. Lin and C. C. Lin, "The in vitro Anti-Herpes Simplex Virus Type-1 and Type-2 Activity of Long Dan Xie Gan Tan, a Prescription of Traditional Chinese Medicine," Chemotherapy, Vol. 54, No. 2, 2008, pp. 77-83. doi:10.1159/000119705

[15] Y. H. Liu and J. C. Dong, "Progress in Pharmacotherapy of Integrated Traditional Chinese and Western Medicine for Virus Infection in Respiratory Tract,” Zhong Xi Yi Jie He Xие Bao, 2004, Vol. 2, No. 3, pp. 226-227. doi:10.3736/jcim20040325 